\title{
THE EVOLUTIONARY PSYCHOLOGY OF LEADERSHIP TRAIT PERCEPTION
}

Kristen K. Knowles

Queen Margaret University, UK

Many researchers now approach the understanding of how facial characteristics shape the perception of leadership ability through the lens of human evolution. Evolutionary psychology considers what skills and characteristics would have been valuable for leaders to possess in our evolutionary history, including dominance, masculinity and trustworthiness. Moreover, it gives an understanding about why rapid categorisation of these social cues from faces is adaptive. In this chapter, I present evolutionary arguments for social inferences based on faces, and discuss how our understanding of this categorisation has shifted away from purely associative phenomena toward evolved, innate processes. I explain how the perception of leadership ability in faces is linked to variance in facial morphology, and how these morphologies tell us something about the individuals who carry them. Specific facial cues relating to leadership-relevant traits are discussed, as well as the underlying biological systems that accompany these traits. I also explain the importance of context and individual differences on the prioritisation of seemingly disparate facial cues to leadership: dominance and trustworthiness. I also discuss recent findings in this area which further extend these concepts to examine cues to leadership in women's faces, generally overlooked by evolutionary psychologists, and how political ideology can interact with these effects. 
THE CASE FOR AN EVOLUTIONARY APPROACH

Facial appearance has a remarkable ability to affect a wide range of social judgements (Todorov \& Oosterhof 2011; Todorov et al., 2013). Far from communicating solely emotional and mental states, facial appearance can also inform a wide range of social trait judgments based on differences in morphology. For example, judgements of traits like attractiveness, dominance and trustworthiness have been linked to differences in facial shape characteristics that vary with facial masculinity (Perrett et al., 1998; Mueller \& Mazur 1997; Oosterhof \& Todorov 2008). That these judgements are generally automatic, reliable and somewhat accurate (see e.g. Bar et al., 2006; Todorov et al., 2009; Willis \& Todorov 2006; Todorov et al., 2008) suggests this stereotyping behaviour may work as a useful heuristic, helping humans to navigate their important and complex social systems.

Indeed, as modern environments differ substantially from evolutionary environments, the role of these heuristic judgements may be even more pronounced. Consider that in historical small-scale societies, ancestral humans are likely to have had first-hand knowledge of any given individual's behavioural qualities, personalities and reputation - information that is unavailable in modern societies, where larger populations make this information more difficult to attain. It is well-established that low-information settings exacerbate reliance on heuristic judgements in decisionmaking (see e.g., Tversky \& Kahneman 1974). This bias also extends to political leadership judgements, which in modern settings are characteristically informationdeprived (Converse 1975; Delli Carpini \& Keeter 1996; Kinder \& Sears 1985). As a 
result of this information deficit, voters are more likely to rely on heuristic judgements to assess leadership competence (Lau \& Redlawsk 2001). It is proposed that voters use information from facial appearance as a heuristic to aid in leadership decisionmaking (Little et al., 2012; Lau \& Redlawsk 2001; Riggle et al., 1992; Antonakis \& Eubanks 2017), particularly in the absence of political knowledge (Ahler et al., 2017; Lenz \& Lawson 2011; Hassin \& Trope 2000).

Historically, these automatic trait inferences have been considered the result of learned associations, developing through the detection and internalisation of regular occurrences (Cogsdill et al., 2014; Fazio et al., 1986; Smith \& DeCoster 2000), but the automaticity and early appearance of face-based trait inferences during development suggests these intuitions are at least partly innate (Saxton et al., 2006; Cogsdill et al., 2014). While some cultural variation exists in the generation and perception of facial expressions (see e.g. Schmidt \& Cohn 2001), many researchers now consider social judgements based on facial morphology as having evolutionary origins (e.g. Feinberg, 2008; Little, Jones, \& DeBruine, 2011; Little \& Roberts, 2012; Puts, Jones, \& DeBruine, 2012; van Vugt \& Grabo, 2015).

Evolutionary approaches to leadership propose that leadership and followership are social structures that are subject to evolutionary mechanisms. It is thought that these structures are the result of recurrent problems in the environment in which humans evolved. The coordination of group members, either in response to the environment or to other groups of people, is believed to have constituted significant evolutionary pressure to facilitate the evolution of a leadership-followership social construct (van Vugt \& Ronay 2014; van Vugt et al., 2008). One such evolved mechanism may 
include the internalisation of leadership prototypes, which are partly based on physiological features (including facial morphology), but are also activated by appropriate contingencies in the environment (van Vugt \& Grabo 2015; van Vugt \& Ronay 2014).

In order to understand the evolutionary roots of these prototypes, we should first consider the environment in which our species evolved, and the environmental and social demands our early hominin ancestors are likely to have faced. The small-scale societies of our evolutionary past suggest an environment in which resource allocation played a key role, particularly with respect to leadership, and scarce resources could be defended and/or seized (Petersen 2015). Naturally, leaders emerge from competition, both between-persons and between-groups, and individuals that are large, strong and aggressive are likely to have distinct advantages in competitive environments. While competition is not the only way to achieve leadership status (see also: experience, problem-solving ability, social prestige), individuals that succeed in intra- and inter-group competition enjoy the biological benefits conferred upon winners of dominance contests, human and nonhuman alike: namely, reproductive success (von Rueden et al., 2011; Cowlishaw \& Dunbar 1991). Furthermore, the ability to quickly and accurately judge an individual's dominance, for example by perceiving facial morphology, may avoid the severe costs associated with a failed contest. Thus, we can consider humans' ability to make rapid and reflexive social judgements based on facial cues as an adaptive quality, conferring survival benefits and avoiding maladaptive costs. 
In this chapter, I will firstly explain the generalised perceptions of dominance and trustworthiness based on facial morphology, how these morphologies are related to leadership characteristics, and how these cues (and the perception thereof) can be the result of evolved mechanisms.

\section{Face research as evolutionary research}

For better or worse, we tend to make social judgements about faces rapidly and reflexively (Oosterhof \& Todorov 2008; Willis \& Todorov 2006; Bar et al., 2006; Todorov et al., 2009). From an evolutionary perspective, these reflexive judgements should serve some functional role. Furthermore, these trait inferences should have particular value when they (1) are based on cues which have evolutionary significance, and (2) the detection of which would be adaptively beneficial ${ }^{1}$.

When evaluating faces on social dimensions, the most salient cues utilised are those to gender, age and ethnicity. Zebrowitz \& Montepare (2008) propose that observers are biased toward perceiving these traits in faces, resulting in an overgeneralisation effect: even when cues to these dimensions are weak, they still elicit a response. It is further argued that stereotyping in this manner is a case of stimulus generalisation (Zebrowitz \& Montepare, 2008). Well-known to cognitive psychologists, stimulus generalization occurs when a novel stimulus elicits a similar response to that generated by a previously encountered, similar stimulus. This overgeneralisation is argued to be an adaptive behaviour- any errors produced by the overgeneralisation are much less costly, compared to failing to respond appropriately in a social situation. That is, a false-positive, such as deferring to a dominant-looking individual

\footnotetext{
${ }^{1}$ See chapter by Petersen, Dubuc \& Higham for a further discussion.
} 
who is submissive in nature, is less costly than a similar false-negative, such as failing to defer to a dominant-looking individual who is aggressive in nature. Because human sociality is complex, and critically important for survival in our evolutionary history, it makes intuitive sense that cognitive mechanisms have evolved to assist navigation of our social environment.

We can also see evolution at work in the specific facial cues which we use to form such generalisations. For example, it is theorised that attractive faces are preferred in leaders because traits which make faces attractive are linked to health, such as masculinity (in males), femininity (in females), symmetry, averageness and youthfulness. In male faces, masculinity is considered a marker of health because testosterone places stress upon the immune system - individuals high in facial masculinity are better able to withstand this stress (Folstad \& Karter 1992). In female faces, femininity is associated with oestrogen and fertility (Thornhill \& Grammer 1999; Law Smith et al., 2006). Symmetry and averageness (how representative a face is within a population; average faces lack idiosyncratic or extreme characteristics) are related to stability during development, evidenced by the absence of childhood illness and stronger immune function. The underlying cause of this developmental stability and immune health is thought to be related to genetic diversity and lack of deleterious alleles in the major histocompatibility complex (MHC) genes, which code for proteins aiding in immune function (Grammer \& Thornhill 1994; Thornhill \& Gangestad 1993; Lie et al., 2008; Rhodes et al., 2001). Youthfulness is also linked to health, with the age-related emergence of many cognitive and physical ailments. The association between facial cues of health and leadership ability is considered adaptive because 
in our evolutionary past, health and physical robustness was necessary for one to obtain and successfully maintain leadership status (Cowlishaw \& Dunbar 1991).

More than just acting as a cue to health and physical prowess, facial masculinity is also used as a cue to secondary behavioural characteristics that are aligned to leadership, including dominance and trustworthiness. Broadly, this is due again to the presence of testosterone, which is needed to develop such facial characteristics (Verdonck et al., 1999; Verdonck et al., 1998). Testosterone is related to a suite of behavioural traits linked to dominance, like aggressiveness, risk-taking, and antisocial behaviour (Mazur \& Booth 1998; Archer 1991; Stanton et al., 2011; Apicella et al., 2008; Coates \& Herbert 2008; Rowe et al., 2004; Dabbs \& Morris 1990). The presence of masculine facial characteristics can consequently be associated with a generalisation of behavioural dominance. Indeed, faces which have been digitally manipulated to appear more masculine receive higher ratings of dominance, and are perceived as being more cold and dishonest; conversely, more feminine male faces are considered cooperative, warm and honest (Perrett et al., 1998).

Our perceptions of leadership ability in faces, and our preferences in who we consider to be a good leader, have underlying biological roots. The characteristics which make a person a good leader (or, at least, good at attaining leadership) can be traced to biological origins, and evolutionary explanations exist for both the presence and the perception of these cues. 


\section{Generalised leadership preferences}

Numerous studies conclude that facial appearance has the ability to affect the outcome of elections. Todorov, Mandisodza, Goren, \& Hall (2005) found that leadership competence ratings based solely on facial appearance predicted the outcomes of U.S. Senate races at rates above chance (up to $73.3 \%$ ). Impressively, these judgements were made after only 1 second of exposure time. Follow-up studies have shown that judgements of competence remain reliable at exposure times of as little as 100 milliseconds (Ballew \& Todorov 2007; Willis \& Todorov 2006), and judgements of trustworthiness may be reliable with exposures of just 39 milliseconds (Bar et al., 2006), suggesting that these leadership-related judgements occur rapidly and reflexively, rather than deliberatively. But, what are the specific facial cues associated with the perception leadership competence?

\section{Masculinity and dominance}

The shape qualities used in most face perception research on leadership ability are based on sexual dimorphism - the difference in shape between male and female faces. See Figure 1. The enlarged jawbones, more prominent cheekbones and pronounced brow ridge are bony structures that characterise a masculine facial appearance and differentiate male faces from female faces (Little et al., 2011; Enlow 1982). This masculine facial shape emerges at puberty, due in part to an increase in male circulating testosterone (Penton-Voak \& Chen 2004). More than simply coinciding at this crucial developmental phase, testosterone appears to have a direct, 
causal link to the growth of these bony structures (Verdonck et al., 1999; Silveira et al., 1992).

\section{FIGURE 1 ABOUT HERE.}

How is the accurate assessment of masculinity adaptive, in an evolutionary sense? A masculine appearance is shaped by testosterone, and testosterone accompanies dominance, aggressiveness and antisocial behavioural qualities (Mazur \& Booth 1998; Archer 1991; Stanton et al., 2011; Apicella et al., 2008; Coates \& Herbert 2008; Rowe et al., 2004; Dabbs \& Morris 1990). The accurate identification of a dominant, aggressive individual would certainly be useful in shaping social responses to such persons, as a mis-step could prove costly if aggressive conflict ensues. Non-human primates that respond inappropriately to social cues are not preferred as social partners, are generally shunned by other group members, and only achieve low dominance ranks themselves (Sackett 1968; Capitanio 1986; Bastian et al., 2003).

Consequently, it is possible to surmise that accurate judgements in this social domain could be adaptively beneficial. Indeed, humans are particularly attuned to markers of physical formidability in faces, body morphology and voices (Sell et al., 2009; Sell et al., 2010).

Relating this to leadership, consider that traits associated with masculinity (dominance, aggressiveness) and femininity (trustworthiness, honesty) could both easily be considered qualities that are important for a leader to possess (van Vugt \& Grabo 2015). In modern human societies, the democratic selection of a group leader is now commonplace, but in social primate species, dominance hierarchies and 
aggressive conflict are ubiquitous (Walters \& Seyfarth 1987). Here, group leaders are more likely to emerge if they have qualities which aid them in dominance contests: e.g. physical prowess, large body size and aggressiveness (Cowlishaw \& Dunbar 1991). It is theorised that humans prefer dominant leaders because these associated traits and behaviours inspire confidence in members of the group. These preferences are further theorised to be exacerbated under conditions of threat or inter-group conflict, when these traits would be considered especially beneficial to the group as a whole (Spisak et al., 2012; Little et al., 2007; van Vugt \& Grabo 2015; Nevicka et al., 2013). See also the following section on context-specific leadership preferences.

Dominance is an important leadership quality in many non-human primate species, not solely because superior fighting ability or body size makes individuals more likely to win agonistic conflicts. In small-scale traditional societies and large-scale democratic societies alike, leaders are often taller, stronger and more behaviourally dominant than their peers (see e.g., Lord, De Vader, \& Alliger, 1986; Maybury-Lewis, 1967; Stulp, Buunk, Verhulst, \& Pollet, 2013; von Rueden, Gurven, Kaplan, \& Stieglitz, 2014; Werner, 1982). Rather than simply enforcing followership through physical coercion, it is thought that dominant individuals may also naturally elicit followership because their appearance reduces conflict in the first instance: a dominant leader can more effectively act as peacekeeper, reducing intra-group conflict (van Vugt 2006). Furthermore, many dominance contests in primates are preceded by demonstrative threat displays that serve to resolve conflict peacefully if one can estimate the strength of their opponent before a conflict takes place, costly escalations are limited. Furthermore, once dominance status has been established between two individuals, the likelihood of violent aggression is minimised, with 
participants favouring threat and avoidance as strategies to resolve conflict with minimal fitness costs. Such conflict avoidance strategies are apparent in humans (Sell 2011), as well as in numerous primate and mammalian species - including rhesus macaques (Bernstein \& Ehardt 1985), chimpanzees (de Waal 1986), gorillas (Sicotte 1993) and wolves (Garcia 1983). In this manner, social groups may live in relative peace with a large, uncontested male as the group leader.

Groups also benefit from dominant leaders because of the access to resources they provide. Large, dominant individuals are likely to have increased fighting and hunting abilities (von Rueden et al., 2014), and are more able to monopolise resources and maintain larger territories, all of which would benefit groups as a whole and inspire freely-conferred leadership status. Von Rueden \& Gurven (2012) suggest that physical dominance may reduce the effort required to coordinate group members, because these dominant individuals can more readily solicit joint attention of group members, thus facilitating group cooperation. Such mechanisms for mutuallybeneficial conflict resolution, freely-conferred followership and group coordination are likely to be favoured by natural selection as they minimise fitness costs at both the individual- and group-level (Silk 1998).

\section{Trustworthiness}

Trustworthiness is also an important quality in a leader. In an experimental study wherein faces were altered to appear more or less trustworthy, participants consistently chose the more trustworthy faces in a hypothetical national leadership election (Little et al., 2012). Cues to facial trustworthiness generally align with femininity: feminised faces receive higher trustworthiness ratings than their 
masculinised counterparts (Perrett et al., 1998). While many species benefit from

274 social hierarchies determined primarily by physical dominance (Smuts et al., 1987;

Considering the apparent relatedness of the dimensions of submissivenessdominance and trustworthiness-untrustworthiness, where submissiveness and trustworthiness may capture similar attributions, Oosterhof \& Todorov (2008) examined both dimensions to model how these map on to social perceptions. The correlation between trustworthiness and dominance attributions was small, and the authors found that the trustworthiness dimension seemed related to valence or emotional state (happy faces appearing more trustworthy), and, to some extent, youthfulness. The dominance dimension seemed more related to masculinity and facial maturity, perhaps due to the age-related emergence of masculine facial characteristics.

While these findings suggest that femininity and trustworthiness may not be captured by the same facial morphologies, and that trustworthiness may be better captured by general valence, studies have found that feminine facial features are related to perceptions of pro-social leadership traits including trustworthiness and cooperativeness. Gladstone \& O'Connor (2014) found that would-be negotiators tended to prefer feminine-faced social partners, perhaps because of an overgeneralisation of submissiveness rather than a desire for a diplomatic, trustworthy counterpart. 
299 Another element of facial trustworthiness is familiarity - the more familiar a face looks, the more we tend to trust it (Buckingham et al., 2006). Rather than pointing to specific morphological facial cues, familiarity and ethnicity both have more to do with the perceiver than the perceived, reflecting the sum of the perceiver's life experience. As such, this is difficult to quantify, but studies do show that when accounting for these factors, we generally prefer our leaders to look like us (DeBruine 2002, 2005;

DeBruine et al., 2008). Using a novel approach to an economic game study,

DeBruine (2002) manipulated faces of playing partners to resemble either (a) the player or an unknown person, or (b) a familiar (famous) person or an unknown person. Manipulations in the direction of the player's own face served to raise the trust given to the partner. That no effect was found for familiar (famous) faces suggests that familiarity may be less important than resemblance. The author suggests that a mechanism of kin-recognition is activated when making these implicit trustworthiness attributions, and this finding is repeated when trustworthiness is judged explicitly (DeBruine 2005). Studies also show that other-race faces are viewed as less trustworthy than own-race faces (Salam et al., 2017; Kubota et al., 2013; Stanley et al., 2011), suggesting that these mechanisms of kin-favouritism might also extend to a general in-group-favouritism (especially when considering the intrinsic relatedness of small-scale societies). Favouring positive social interactions with individuals who resemble oneself chimes with kin selection theory (Hamilton 1964), which suggests individuals will show biases in social interactions toward those who share genetic relatedness. The subtle fitness advantages conferred upon relatives increases the inclusive fitness of the individual, thus perpetuating the behavioural bias (DeBruine et al., 2008; Hamilton 1964). 
324 This trustworthiness of self-similarity may be related to facial averageness - how representative a given face is, based on the population, or rather, how close the facial configuration is to the population mean. Early evidence in this domain pointed to averageness being more important than self-similarity on judgements of attractiveness (Penton-Voak et al., 1999). To a certain degree, averageness is considered a marker of developmental stability and genetic diversity, both themselves indicators of a strong immune system (Thornhill \& Gangestad 1999; Penn et al., 2002). Average faces are considered attractive and trustworthy, while anomalous or idiosyncratic faces receive generally negative stereotypes (Langolis \& Roggman 1990; Langolis et al., 1994; Zebrowitz et al., 2003). Although Zebrowitz and colleagues interpret these findings as an overgeneralisation of responses to unfit or unhealthy individuals, it may be that anomalous faces are non-average (divergent from the population mean) and therefore appear visually similar to faces of fewer individuals. A simpler explanation may be that positive attributions (like perceived attractiveness (Eagly et al., 1991; Dion et al., 1972).

In the preceding pages, I have discussed how both dominance and trustworthiness can be considered valued leadership qualities, and detailed how both of these traits can be perceived based upon facial morphological features. It is notable that facial dominance and trustworthiness are not the only routes to perceptions of leadership competence. One such further example centres on the age of the individual; facial age is associated with leadership ability, inasmuch as it is considered a proxy for 
experience. Moreover, this experience may be more important in certain leadership contexts. For example, there is some evidence that older (more-experienced) leaders are preferred during times of stability, while younger (more-exploratory) leaders are preferred during times of change (Spisak et al., 2014). What follows is a summation of a current direction in this research area: how leadership qualities can be differently favoured, based on the task at hand.

\section{Task-congruent leadership preferences}

As covered in the preceding sections, a number of traits are associated with leadership ability. While some of these traits may be generally valued in leadership (e.g., trustworthiness), others may be prioritised differently according to the specific leadership situation. Dominance and trustworthiness fail to fit together neatly as leadership qualities, behaviourally sitting at opposing ends of a continuum. Much of the difference between these traits seems to be captured by variation in masculinity/femininity. Masculinity is generally aligned with untrustworthiness, dominance and dishonesty, while femininity is aligned with trustworthiness, honesty and diplomacy (Perrett et al., 1998). How could it be that apparent opposites could both be considered important characteristics of a leader?

In real-world leadership choices, whether choosing a leader to run a football team, a company or a country, many factors can influence how we conceptualise what would make a good leader. For example, if a country is at war, voters may prioritise leadership qualities that reflect masculine and dominant characteristics. Conversely, in peacetime, more feminine and diplomatic qualities may be more strongly valued by 
voters. Such a tradeoff is known as task-congruent selection (Little 2014; Little \& Roberts 2012): that is, we value different leadership qualities based on the task for which the leader is being chosen.

The first study to experimentally demonstrate this effect in faces examined shape differences in masculinity. When asked to choose a hypothetical national leader, participants showed no clear preference for either masculinised or feminised faces. However, when the context of voting was changed to wartime, participants generally preferred masculinised faces; in peacetime, feminised faces were chosen to a greater degree (Little et al., 2007). This finding also extended to faces that were manipulated to resemble real politicians. Manipulating images based on the difference in face shape between George W. Bush and John Kerry (former-president Bush's lead opponent in 2004), Little et al., (2007) were able to create novel face stimuli that looked more like one candidate, and less like the other. When participants were asked to choose a hypothetical national leader during a time of war from these manipulated images, voters generally preferred the faces which looked more like Bush (and less like Kerry). When making the same decision during a time of peace, participants preferred the faces which were manipulated to look more like Kerry (and less like Bush). At the time of the Bush-Kerry presidential race, the U.S. was engaged in the Iraq war, and constituents were still largely unsettled by the 2001 terror attacks. These findings were the first of their kind to show the importance of context on the way differing leadership traits could be prioritised, with implications in real-world electoral outcomes. Many studies have since examined similar concepts, showing general agreement that masculine/dominant facial features are favoured during times of war, and feminine/trustworthy faces are favoured during times of 
peace, or when cooperation/diplomacy is prioritised. A summary of these research findings is provided in Table 1.

\section{TABLE 1 ABOUT HERE.}

It makes intuitive sense that we prefer different behavioural traits in leaders based on the leadership task for which they are being selected. It may surprise many that we make such decisions based, in part, on automatic attributions drawn from facial characteristics. That we can make such judgements in a heuristic manner, rather than entirely deliberatively, serves humans well in navigating complicated social systems. The question regarding whether these task-congruent preferences are evolved or learned by association warrants discussion. Historical accounts and accounts of modern hunter-gatherer societies, which more closely resemble early human groups, show similar evidence for task-congruent leadership. Price \& van Vugt (2014) report that the Cheyenne (a native American tribe) had more aggressive and younger leaders during times of war, while peacetime brought leaders who were more skilled at diplomacy than violence (van Vugt \& Grabo 2015).

Little (2014) demonstrates that these task-contingent judgements are both implicit and learned. After first showing that masculinity is favoured in wartime over peacetime contexts, a follow-up study revealed that it is also possible to learn facebehaviour associations. By manipulating an arbitrary facial feature (distance between eyes) and pairing these differences with short descriptions of the individual (for example, "...helps children in training for various sports, including boxing," versus, "volunteers his time at a care home for the elderly"), it was possible to learn 
associations between physical prowess or cooperation and the arbitrary facial features. Results of the study showed that indeed, participants were more likely to choose leaders for competitive or cooperative tasks that had task-congruent facial features in the learning trials. This shows that while implicit associations are unlearned and reflexive, it is also possible that an element of associative learning takes place in the accumulation of life experience.

\section{Current directions: Women's faces and political ideology}

A limitation of existing research in this area is that it largely ignores female facial cues to leadership competencies. Women are generally omitted from this type of research because of their historically limited access to leadership positions. In tribal or huntergatherer societies, sexually-dimorphic characteristics relating to body size and aggressiveness leave women de facto excluded from leadership roles. The implicit non-dominance of females (relative to males) may account, in part, for women's tendency to obtain an overall lesser degree of political influence, at least in traditional/historical societies (von Rueden et al., 2014).

Nevertheless, in modern societies, women obtain leadership roles in ever-increasing numbers, and face research in relation to women and leadership is still overall lacking. Increasing the attractiveness of female (and male) faces improves their likelihood of being elected (Berggren et al., 2010), but there are surely many other factors to explore within women's faces beyond attractiveness. For example, while dominance and masculinity can be considered leadership-appropriate qualities in male leaders, for women, these qualities tend to come with a "dominance penalty." Both implicit and explicit dominance behaviour in women tends to draw more 
negative attributions, including a decrease in hireability (for a review, see Williams \& Tiedens 2016). Interesting research has been developed recently, which suggests this relates to a gender-typicality of appearance (and thus, implicit behavioural qualities). Carpinella, Hehman, Freeman, \& Johnson (2016) report that US conservatives tend to prefer a greater degree of gender-typicality in both male and female political candidates - that is, they prefer men to appear more masculine, and women to appear more feminine, compared with US liberals, who do not exhibit such preferences.

By examining differences in ratings of leadership ability in America pre- and post9/11, Falk \& Kenski (2006) showed that differences in perceived external threats can influence a preference for male leadership over female leadership. This male preference was more pronounced for conservative voters than for liberal voters, suggesting that political ideology can interact with preferences for masculine leadership prototypes, either by moderating (a) the perceived level of threat, or (b) the preferred responses to threat. Indeed, research has shown that conservative voters tend to see the world as generally more threatening and competitive than liberal voters, who view the world as more peaceful and cooperative (for a review, see Jost, Federico, \& Napier, 2009). Laustsen (2016) suggests that this difference in perceived threat, based on political ideology, has the potential to influence genderspecific and context-specific leadership choices.

\section{Summary and Conclusions}


When considering the evolved psychological mechanisms for the perception of

473 leadership in faces, it is important to consider what skills and characteristics would

have been valuable for leaders to possess in our evolutionary history. Human sociality is complex and important, and cognitive heuristics which allow for rapid and reflexive social judgements are sure to aid in navigating these social systems. By guiding appropriate responses to others, these shortcuts allow individuals to benefit from rapid categorisation of social signals, and avoid maladaptive costs associated with inappropriate responses.

The perception of leadership ability in faces is linked to variance in facial morphology, and these morphologies tell us something about the individuals who carry them. Testosterone, which influences facial masculinity and immune health, is also related to behavioural dominance. Recognising individuals who are dominant, both physically and behaviourally, is a valuable skill. Groups benefit from the leadership of dominant individuals because of the protection, territory and resources they are able to secure. Dominant individuals may also provide stability to groups because stable dominance hierarchies reduce intra-group competition and increase group cooperation and coordination.

Trustworthiness and dominance are two characteristics that are valued in leaders, but these traits may be conceptually different: trustworthiness perhaps relating more to valence or behavioural disposition, and dominance relating more to masculinity/femininity. Differing scenarios can prioritise whether a trustworthy or a dominant leader is valued - dominant/masculine leaders are preferred during times of war, conflict and uncertainty, while trustworthy/feminine leaders are preferred 
during times of peace, when diplomacy and cooperation are more valued as leader characteristics. Recent research expands these concepts to include women as political leaders, and individual differences (such as political ideology) that can interact with these effects. The perception of leadership ability has much to do with the face of the proposed leader, but situational contexts and individual differences on part of the perceivers are beginning to be better understood.

\section{REFERENCES}

Ahler, D. J., Citrin, J., Dougal, M. C., \& Lenz, G. S. (2017). Face value? Experimental evidence that candidate appearance influences electoral choice. Political Behavior, 39(1), 77-102.

Antonakis, J., \& Eubanks, D. L. (2017). Looking Leadership in the Face. Current Directions in Psychological Science, 26(3), 270-275.

Apicella, C. L., Dreber, A., Campbell, B., Gray, P. B., Hoffman, M., \& Little, A. C. (2008). Testosterone and financial risk preferences. Evolution and Human Behavior, 29(6), 384-390.

Archer, J. (1991). The influence of testosterone on human aggression. British Journal of Psychology, 82, 1-28. (MISSING ISSUE??)

Ballew, C. C., \& Todorov, A. (2007). Predicting political elections from rapid and unreflective face judgments. Proceedings of the National Academy of Sciences of the United States of America, 104(46), 17948-17953.

Bar, M., Neta, M., \& Linz, H. (2006). Very first impressions. Emotion, 6(2), 269-78. Bastian, M. L., Sponberg, A. C., Suomi, S. J., \& Higley, J. D. (2003). Long-term effects of infant rearing condition on the acquisition of dominance rank in juvenile and adult rhesus macaques (Macaca mulatta). Developmental Psychobiology, 42(1), 4451.

Berggren, N., Jordahl, H., \& Poutvaara, P. (2010). The looks of a winner: Beauty and electoral success. Journal of Public Economics, 94, 8-15. (MISSING ISSUE??)

Bernstein, I. S., \& Ehardt, C. L. (1985). Intragroup agnostic behavior in rhesus monkeys (Macaca mulatta). International Journal of Primatology, 6(3), 209-226.

Buckingham, G., DeBruine, L. M., Little, A. C., Welling, L. L. M., Conway, C. A., Tiddeman, B. P., \& Jones, B. C. (2006). Visual adaptation to masculine and feminine faces influences generalized preferences and perceptions of trustworthiness. 
Evolution and Human Behavior, 27(5), 381-389.

Capitanio, J. P. (1986). Behavioral pathology. In G. Mitchell \& J. Erwin (Eds.), Comparative primate biology: Behavior, conservation, and ecology (pp. 411-454). New York: Alan R. Liss.

Carpinella, C. M., Hehman, E., Freeman, J. B., \& Johnson, K. L. (2016). The gendered face of partisan politics: Consequences of facial sex typicality for vote choice appearance-based politics. Political Communication, 33, 21-38. (MISSING ISSUE??)

Coates, J. M., \& Herbert, J. (2008). Endogenous steroids and financial risk taking on a London trading floor. Proceedings of the National Academy of Sciences of the United States of America, 105(16), 6167-6172.

Cogsdill, E. J., Todorov, A. T., Spelke, E. S., \& Banaji, M. R. (2014). Inferring character from faces: A developmental study. Psychological Science, 25(5), 11321139.

Converse, P. E. (1975). Public opinion and voting behavior. In F. I. Greenstein \& N. W. Polsby (Eds.), Handbook of Political Science, Vol. 4. Reading, Mass: AddisonWesley.

Cowlishaw, G., \& Dunbar, R. I. M. (1991). Dominance rank and mating success in male primates. Animal Behaviour, 41(6), 1045-1056.

Dabbs, J. M., \& Morris, R. (1990). Testosterone, social class, and antisocial behavior in a sample of 4,462 men. Psychological Science, 1(3), 209-211.

de Waal, F. B. M. (1986). The integration of dominance and social bonding in primates. The Quarterly Review of Biology, 61(4), 459-479.

DeBruine, L. M. (2002). Facial resemblance enhances trust. Proceedings of the Royal Society B: Biological Sciences, 269(1498), 1307-1312.

DeBruine, L. M. (2005). Trustworthy but not lust-worthy: Context-specific effects of facial resemblance. Proceedings of the Royal Society B: Biological Sciences, 272, 919-922.

DeBruine, L. M., Jones, B. C., Little, A. C., \& Perrett, D. I. (2008). Social perception of facial resemblance in humans. Archives of Sexual Behavior, 37(1), 64-77.

Delli Carpini, M., \& Keeter, S. (1996). What Americans Know About Politics and Why It Matters. New Haven: Yale University Press.

Dion, K., Berscheid, E., \& Walster, E. (1972). What is beautiful is good. Journal of Personality and Social Psychology, 24(3), 285-290.

Eagly, A. H., Ashmore, R. D., Makhijani, M. G., \& Longo, L. C. (1991). What is beautiful is good, but... : A meta-anatytic review of research on the physical 
attractiveness stereotype. Psychological Bulletin, 110(1), 109-128. doi:10.1037//0033-2909.110.1.109

Enlow, D. M. (1982). Handbook of facial growth (2nd ed.). Philadelphia: Saunders. Falk, E., \& Kenski, K. (2006). Issue saliency and gender stereotypes: Support for women as presidents in times of war and terrorism. Social Science Quarterly, 87(1), $1-18$.

Fazio, R. H., Sanbonmatsu, D. M., Powell, M. C., \& Kardes, F. R. (1986). On the automatic activation of attitudes. Journal of Personality and Social Psychology, 50(2), 229-238.

Feinberg, D. R. (2008). Are human faces and voices ornaments signaling common underlying cues to mate value? Evolutionary Anthropology, 17(2), 112-118.

Folstad, I., \& Karter, A. J. (1992). Parasites, bright males, and the immunocompetance handicap. The American Naturalist, 139(3), 603-622.

Garcia, A. (1983). On the social behaviour of maned wolves (Chrysocyon brachyurus). Beletim de Zoologia, 6(6), 63-77.

Gladstone, E., \& O'Connor, K. M. (2014). A counterpart's feminine face signals cooperativeness and encourages negotiators to compete. Organizational Behavior and Human Decision Processes, 125, 18-25. (MISSING ISSUE??)

Grammer, K., \& Thornhill, R. (1994). Human (Homo sapiens) facial attractiveness and sexual selection: the role of symmetry and averageness. Journal of Comparative Psychology, 108(3), 233-242.

Hamilton, W. D. (1964). The genetical evolution of social behaviour. Part I. Journal of Theoretical Biology, 7(1), 17-52.

Hassin, R., \& Trope, Y. (2000). Facing faces: Studies on the cognitive aspects of physiognomy. Journal of Personality and Social Psychology, 78(5), 837-852.

Jost, J. T., Federico, C. M., \& Napier, J. L. (2009). Political ideology: Its structure, functions, and elective affinities. Annual Review of Psychology, 60, 307-337. (MISSING ISSUE??)

Kinder, D. R., \& Sears, D. O. (1985). Public opinion and political action. In G. Lindzey \& E. Aronson (Eds.), Handbook of Social Psychology, Vol. 2 (3rd ed.). New York: Random House.

Kubota, J. T., Li, J., Bar-David, E., Banaji, M. R., \& Phelps, E. A. (2013). The price of racial bias: Intergroup negotiations in the ultimatum game. Psychological Science, 24(12), 2498-2504.

Langolis, J. H., \& Roggman, L. A. (1990). Attractive faces are only average.

Psychological Science, 1(2), 115-121. 
Langolis, J. H., Roggman, L. A., \& Musselman, L. (1994). What is average and what is not average about attractive faces? Psychological Science, 5(4), 214-220.

Lau, R. R., \& Redlawsk, D. P. (2001). Heuristics in political decision making. American Journal of Political Science, 45(4), 951-971.

Laustsen, L. (2016). Choosing the right candidate: Observational and experimental evidence that conservatives and liberals prefer powerful and warm candidate personalities, respectively. Political Behavior, 1-26.

Laustsen, L., \& Petersen, M. B. (2015). Does a competent leader make a good friend? Conflict, ideology and the psychologies of friendship and followership. Evolution and Human Behavior, 36(4), 286-293.

Law Smith, M. J., Perrett, D. I., Jones, B. C., Cornwell, R. E., Moore, F. R., Feinberg, D. R., ... Hillier, S. G. (2006). Facial appearance is a cue to oestrogen levels in women. Proceedings of the Royal Society B: Biological Sciences, 273(1583), 135140.

Lenz, G. S., \& Lawson, C. (2011). Looking the part: Television leads less informed citizens to vote based on candidates' appearance. American Journal of Political Science, 55(3), 574-589.

Lie, H. C., Rhodes, G., \& Simmons, L. W. (2008). Genetic diversity revealed in human faces. Evolution, 62(10), 2473-2486.

Little, A. C. (2014). Facial appearance and leader choice in different contexts: Evidence for task contingent selection based on implicit and learned facebehaviour/face-ability associations. The Leadership Quarterly, 25(5), 865-874.

Little, A. C., Burriss, R. P., Jones, B. C., \& Roberts, S. C. (2007). Facial appearance affects voting decisions. Evolution and Human Behavior, 28(1), 18-27.

Little, A. C., Jones, B. C., \& DeBruine, L. M. (2011). Facial attractiveness: evolutionary based research. Philosophical Transactions of the Royal Society of London. Series B, Biological Sciences, 366(1571), 1638-59.

Little, A. C., \& Roberts, S. C. (2012). Evolution, appearance, and occupational success. Evolutionary Psychology, 10(5), 782-801.

Little, A. C., Roberts, S. C., Jones, B. C., \& Debruine, L. M. (2012). The perception of attractiveness and trustworthiness in male faces affects hypothetical voting decisions differently in wartime and peacetime scenarios. Quarterly Journal of Experimental Psychology, 65(10), 2018-2032.

Lord, R. G., De Vader, C. L., \& Alliger, G. M. (1986). A meta-analysis of the relation between personality traits and leadership perceptions: An application of validity generalization procedures. Journal of Applied Psychology, 71(3), 402-410.

Maybury-Lewis, D. (1967). Akwe-Shavante Society: Social Organization of a 
Brazilian Tribe. Oxford: Oxford University Press.

Mazur, A., \& Booth, A. (1998). Testosterone and dominance in men. Behavioral and Brain Sciences, 21, 353-397. doi:10.1017/S0140525X98001228

Mueller, U., \& Mazur, A. (1997). Facial dominance in Homo sapiens as honest signalling of male quality. Behavioral Ecology, 8(5), 569-579.

Nevicka, B., De Hoogh, A. H. B., Van Vianen, A. E. M., \& Ten Velden, F. S. (2013). Uncertainty enhances the preference for narcissistic leaders. European Journal of Social Psychology, 43(5), 370-380.

Oosterhof, N. N., \& Todorov, A. (2008). The functional basis of face evaluation. Proceedings of the National Academy of Sciences of the United States of America, 105(32), 11087-11092.

Penn, D. J., Damjanovich, K., \& Potts, W. K. (2002). MHC heterozygosity confers a selective advantage against multiple-strain infections. Proceedings of the National Academy of Sciences of the United States of America, 99, 11260-11264.

Penton-Voak, I. S., \& Chen, J. Y. (2004). High salivary testosterone is linked to masculine male facial appearance in humans. Evolution and Human Behavior, 25(4), 229-241.

Penton-Voak, I. S., Perrett, D. I., \& Peirce, J. W. (1999). Computer graphic studies of the role of facial similarity in judgements of attractiveness. Current Psychology, 18(1), 104-118.

Perrett, D. I., Lee, K. J., Penton-Voak, I. S., Rowland, D., Yoshikawa, S., Burt, D. M., ... Akamatsu, S. (1998). Effects of sexual dimorphism on facial attractiveness. Nature, 394, 884-887.

Petersen, M. B. (2015). Evolutionary political psychology: On the origin and structure of heuristics and biases in politics. Political Psychology, 36(S1), 45-78.

Price, M. E., \& van Vugt, M. (2014). The evolution of leader-follower reciprocity: The theory of service-for-prestige. Frontiers in Human Neuroscience, 8, 363.

Puts, D. A., Jones, B. C., \& DeBruine, L. M. (2012). Sexual selection on human faces and voices. Journal of Sex Research, 49(2-3), 227-243.

Rhodes, G., Zebrowitz, L. A., Clark, A., Kalick, S. M., Hightower, A., \& McKay, R. (2001). Do facial averageness and symmetry signal health? Evolution and Human Behavior, 22(1), 31-46.

Riggle, E. D., Ottaki, V. C., Wyer, R. S., Kuklinski, J., \& Schwarz, N. (1992). Bases of political judgements: The role of stereotypic and non- stereotypic information. Political Behavior, 14(17), 67-87.

Rowe, R., Maughan, B., Worthman, C. M., Costello, E. J., \& Angold, A. (2004). 
Testosterone, antisocial behavior, and social dominance in boys: pubertal development and biosocial interaction. Biological Psychiatry, 55(5), 546-552.

Sackett, G. P. (1968). Abnormal behavior in laboratory-reared rhesus monkeys. In M. W. Fox (Ed.), Abnormal behavior in animals (pp. 293-331). St. Louis: W.B. Saunders.

Salam, A. P., Rainford, E., van Vugt, M., \& Ronay, R. (2017). Acute Stress Reduces Perceived Trustworthiness of Male Racial Outgroup Faces. Adaptive Human Behavior and Physiology, 3(4), 282-292.

Saxton, T. K., Caryl, P. G., \& Roberts, S. C. (2006). Vocal and Facial Attractiveness Judgments of Children, Adolescents and Adults: the Ontogeny of Mate Choice. Ethology, 112(12), 1179-1185.

Schmidt, K. L., \& Cohn, J. F. (2001). Human facial expressions as adaptations: Evolutionary questions in facial expression research. Yearbook of Physical Anthropology, 44, 3-24.

Sell, A. (2011). Applying adaptationism to human anger: The recalibrational theory. In P. R. Shaver \& M. Mikulincer (Eds.), Human aggression and violence: Causes, manifestations, and consequences (pp. 53-70). Washington, DC: American Psychological Association.

Sell, A., Bryant, G. A., Cosmides, L., Tooby, J., Sznycer, D., von Rueden, C., ... Gurven, M. (2010). Adaptations in humans for assessing physical strength from the voice. Proceedings of the Royal Society B: Biological Sciences, 277(1699), 35093518.

Sell, A., Cosmides, L., Tooby, J., Sznycer, D., von Rueden, C., \& Gurven, M. (2009). Human adaptations for the visual assessment of strength and fighting ability from the body and face. Proceedings of the Royal Society B: Biological Sciences, 276, 575584.

Sicotte, P. (1993). Inter-group encounters and female transfer in mountain gorillas: Influence of group composition on male behavior. American Journal of Primatology, 30, 21-36. (MISSING ISSUE??)

Silk, J. B. (1998). Making amends: Adaptive perspectives on conflict remediation in monkeys, apes, and humans. Human Nature, 9(4), 341-368.

Silveira, A. M., Fishman, L. S., Subtelny, J. D., \& Kassebaum, D. K. (1992). Facial growth during adolescence in early, average and late maturers. The Angle Orthodontist, 62(3), 185-190.

Smith, E. R., \& DeCoster, J. (2000). Dual-process models in social and cognitive psychology: Conceptual integration and links to underlying memory systems. Personality and Social Psychology Review, 4(2), 108-131.

Smuts, B. B., Cheney, D. L., Seyfarth, R. M., Wrangham, R. W., \& Struhsaker, T. T. (Eds.). (1987). Primate Societies. Chicago: University of Chicago Press. 
Spisak, B. R. (2012). The general age of leadership: Older-looking presidential candidates win elections during war. PLOS ONE, 7(5), e36945.

Spisak, B. R., Dekker, P. H., Krüger, M., \& van Vugt, M. (2012). Warriors and peacekeepers: testing a biosocial implicit leadership hypothesis of intergroup relations using masculine and feminine faces. PloS One, 7(1), e30399.

Spisak, B. R., Grabo, A. E., Arvey, R. D., \& van Vugt, M. (2014). The age of exploration and exploitation: Younger-looking leaders endorsed for change and olderlooking leaders endorsed for stability. The Leadership Quarterly, 25(5), 805-816.

Spisak, B. R., Homan, A. C., Grabo, A., \& van Vugt, M. (2012). Facing the situation: Testing a biosocial contingency model of leadership in intergroup relations using masculine and feminine faces. The Leadership Quarterly, 23(2), 273-280.

Stanley, D. A., Sokol-Hessner, P., Banaji, M. R., \& Phelps, E. A. (2011). Implicit race attitudes predict trustworthiness judgments and economic trust decisions. Proceedings of the National Academy of Sciences, 108(19), 7710-7715.

Stanton, S. J., Liening, S. H., \& Schultheiss, O. C. (2011). Testosterone is positively associated with risk taking in the lowa Gambling Task. Hormones and Behavior, 59(2), 252-256.

Stulp, G., Buunk, A. P., Verhulst, S., \& Pollet, T. V. (2013). Tall claims? Sense and nonsense about the importance of height of US presidents. The Leadership Quarterly, 24(1), 159-171.

Thornhill, R., \& Gangestad, S. W. (1993). Human facial beauty: Averageness, aymmetry, and parasite resistance. Human Nature, 4(3), 237-269.

Thornhill, R., \& Gangestad, S. W. (1999). Facial attractiveness. Trends in Cognitive Sciences, 3(12), 452-460.

Thornhill, R., \& Grammer, K. (1999). The Body and Face of Woman: One Ornament that Signals Quality? Evolution and Human Behavior, 20, 105-120.

Todorov, A., Mandisodza, A. N., Goren, A., \& Hall, C. C. (2005). Inferences of competence from faces predict election outcomes. Science, 308(5728), 1623-1626.

Todorov, A., Mende-Siedlecki, P., \& Dotsch, R. (2013). Social judgments from faces. Current Opinion in Neurobiology, 23(3), 373-380.

Todorov, A., \& Oosterhof, N. (2011). Modeling social perception of faces. IEEE Signal Processing Magazine, 28, 117-122.

Todorov, A., Pakrashi, M., \& Oosterhof, N. N. (2009). Evaluating faces on trustworthiness after minimal time exposure. Social Cognition, 27(6), 813-833.

Todorov, A., Said, C. P., Engell, A. D., \& Oosterhof, N. N. (2008). Understanding evaluation of faces on social dimensions. Trends in Cognitive Sciences, 12(12), 455- 
460.

Tversky, A., \& Kahneman, D. (1974). Judgment under uncertainty. Science, 185(4157), 1124-1131.

van Vugt, M. (2006). Evolutionary origins of leadership and followership. Personality and Social Psychology Review, 10(4), 354-371.

van Vugt, M., \& Grabo, A. E. (2015). The many faces of leadership: An evolutionarypsychology approach. Current Directions in Psychological Science, 24(6), 484-489.

van Vugt, M., Hogan, R., \& Kaiser, R. B. (2008). Leadership, followership, and evolution: some lessons from the past. The American Psychologist, 63(3), 182-196.

van Vugt, M., \& Ronay, R. (2014). The evolutionary psychology of leadership: Theory, review, and roadmap. Organizational Psychology Review, 4(1), 74-95.

Verdonck, A., De Riddera, L., Kühnc, R., Darrasc, V., Carelsa, C., \& de Zegherd, F. (1998). Effect of testosterone replacement after neonatal castration on craniofacial growth in rats. Archives of Oral Biology, 43(7), 551-557.

Verdonck, A., Gaethofs, M., Carels, C., \& de Zegher, F. (1999). Effect of low-dose testosterone on craniofacial growth in boys with delayed puberty. European Journal of Orthodontics, 21, 137-143. (MISSING ISSUE??)

von Rueden, C., \& Gurven, M. (2012). When the strong punish: Why net costs of punishment are often negligible. Behavioral and Brain Sciences, 35, 43-44.

von Rueden, C., Gurven, M., \& Kaplan, H. (2011). Why do men seek status? Fitness payoffs to dominance and prestige. Proceedings of the Royal Society B: Biological Sciences, 278, 2223-2232.

von Rueden, C., Gurven, M., Kaplan, H., \& Stieglitz, J. (2014). Leadership in an egalitarian society. Human Nature, 25(4), 538-566.

Walters, J. R., \& Seyfarth, R. M. (1987). Conflict and cooperation. In B. B. Smuts, D. L. Cheney, R. M. Seyfarth, R. W. Wrangham, \& T. T. Struhsacker (Eds.), Primate Societies (pp. 306-317). Chicago, IL: University of Chicago Press.

Werner, D. (1982). Chiefs and presidents: A comparison of leadership traits in the United States and among the Mekranoti-Kayapo of central Brazil. Ethos, 10(2), 136148.

Williams, M. J., \& Tiedens, L. Z. (2016). The subtle suspension of backlash: A metaanalysis of penalties for women's implicit and explicit dominance behavior.

Psychological Bulletin, 142(2), 165-197.

Willis, J., \& Todorov, A. (2006). First impressions: making up your mind after a 100ms exposure to a face. Psychological Science, 17(7), 592-598.

Zebrowitz, L. A., Fellous, J. M., Mignault, A., \& Andreoletti, C. (2003). Trait 
891 impressions as overgeneralized responses to adaptively significant facial qualities:

892 Evidence from connectionist modeling. Personality and Social Psychology Review, $8937(3), 194-215$.

Zebrowitz, L. A., \& Montepare, J. M. (2008). Social psychological face perception: Why appearance matters. Social and Personality Psychology Compass, 2, 14971517. 